\title{
How (i)rrational are we? A case of Croatian inflation
}

\author{
Nataša Erjavec ${ }^{1}$, Ivana Lolić ${ }^{1}$ and Petar Soricíc, ${ }^{1 *}$ \\ ${ }^{1}$ Faculty of Economics and Business Zagreb, University of Zagreb \\ Trg J. F. Kennedya 6, 10000 Zagreb, Croatia \\ E-mail: 〈\{nerjavec, ilolic, psoric\}@efzg.hr〉
}

\begin{abstract}
This paper examines the validity of the rational expectations hypothesis $(\mathrm{REH})$ in the case of Croatian consumers and their inflation estimates. The added value of this paper in comparison to previous similar studies lies in the state space methodology, allowing the authors to test for potential time variability of the estimated relationship between actual and expected inflation. The obtained results can be summarized as follows: $i$ ) consumers heavily over-estimated actual inflation throughout the entire period 2005-2014, leading to the rejection of the REH; ii) consumer bias against inflation intensifies in times of abrupt price hikes (2007 and 2008), and diminishes in times of lower inflation volatility (2014). This empirical rejection of the $\mathrm{REH}$ is in line with previous research on the topic, providing additional evidence that the theoretical paradigm of homo economicus is heavily flawed.
\end{abstract}

Key words: inflation expectations, rational expectations hypothesis, state space model, consumer surveys, time-varying parameters

Received: September 21, 2014; accepted: March 17, 2015; available online: March 30, 2015

DOI: $10.17535 /$ crorr.2015.0019

\section{Introduction}

The rational expectations hypothesis (REH) today presents the workhorse model of modern macroeconomics. It is widely accepted that economic agents are utterly rational and fully informed, taking into account all relevant information when making economic decisions. For example, the REH can be found in the microeconomic foundations of the New Keynesian Phillips curve [10] and in the vast number of highly popular dynamic stochastic general equilibrium models (see e.g. [4] for an excellent analysis of the REH in modern macro).

However, the fact that most macro models employ the rationality assumption does not necessarily mean it is true. Specifically, "it is important to study how the expectations of real people, not a model's rational agents, are

${ }^{*}$ Corresponding author. 
actually formed" [4]. This paper aims to make a contribution to existing literature by analyzing whether the $\mathrm{REH}$ holds in the case of Croatian consumers and their inflation expectations. Since previous studies on this issue have focused entirely on linear econometric models, this paper investigates whether time-varying econometric models offer new insights on the matter. Even if the REH does not hold in a nonlinear framework, this approach offers the opportunity to unveil the time dynamics of the observed relationship. This is important for at least two reasons. Firstly, research has documented that consumer expectations react more intensively in times of substantial price growths [18]. Secondly, voices have been raised that EU accession would induce significant price changes for various Croatian goods and services [15]. This might lead to varying rationality, i.e. consumers might react differently to actual price changes, depending on the said two exogenous interventions.

\section{Literature review}

Literature covering the subject of consumer rationality concerning inflation has become quite extensive over the years. However, different authors use various methods for uncovering inflation expectations, focusing on different countries and various econometric techniques. As a result, the obtained conclusions diverge extensively. Some of the milestone studies are presented in Table 1.

\begin{tabular}{|c|c|c|c|}
\hline Study & Country & $\begin{array}{c}\text { Estimation } \\
\text { method }\end{array}$ & $\begin{array}{c}\text { Characteristics of } \\
\text { inflation } \\
\text { expectations }\end{array}$ \\
\hline Gramlich (1983) & USA & OLS & $\begin{array}{c}\text { Biased and } \\
\text { inefficient }\end{array}$ \\
\hline Bakhshi and Yates (1988) & UK & $\begin{array}{c}\text { Engle-Granger } \\
\text { cointegration }\end{array}$ & Biased \\
\hline Forsells and Kenny (2004) & Euro area & $\begin{array}{c}\text { OLS/Johansen } \\
\text { cointegration }\end{array}$ & $\begin{array}{c}\text { 'Intermediate' } \\
\text { form of } \\
\text { rationality }\end{array}$ \\
\hline $\begin{array}{c}\text { Kokoszczyński, Lyziak and } \\
\text { Stanisławska (2006) }\end{array}$ & $\begin{array}{c}\text { Poland and } \\
\text { Czech Republic }\end{array}$ & OLS & Biased \\
\hline Sabrowski (2008) & Germany & OLS & Biased \\
\hline Sorić, Lolić and Mačkić (2014) & $\begin{array}{c}24 \text { individual } \\
\text { EU countries }\end{array}$ & $\begin{array}{c}\text { OLS/Johansen } \\
\text { cointegration }\end{array}$ & Mixed evidence \\
\hline
\end{tabular}

Table 1: Literature review

The REH is founded on two separate cornerstones. It presumes that: $i$ ) consumers are able to accurately predict actual inflation developments (unbiased expectations), and ii) macroeconomic variables (monetary aggregates, exchange rate, interest rates, etc.) do not significantly feed into consumer expectations errors (efficient expectations). 
The evidence in Table 1 shows that the vast majority of relevant studies find that consumers are not able to generate unbiased estimates of inflation. However, a glance at the column estimation method reveals that all the above papers employ strictly linear econometric techniques, analyzing the 'on average' relationship between actual and expected inflation. It would also be plausible to raise the question of the potential time variability of model parameters. With that in mind, this paper applies the state space methodology in order to inspect whether the inflation expectations of Croatian consumers are unbiased at least in certain parts of the analyzed period (if not throughout the entire period).

\section{Data issues and quantification of inflation expectations}

Data from a consumer survey were analyzed to directly measure actual inflation expectations. Specifically, responses to the question below from The Joint Harmonised EU Programme of Business and Consumer Surveys [8] were considered for the Croatian economy.

Q6 By comparison with the past 12 months, how do you expect that consumer prices will develop in the next 12 months? They will ...

a) increase more rapidly , b) increase at the same rate, c) increase at a slower rate, d) stay about the same, e) fall, f) don't know.

Interviews were conducted on a sample of 1000 Croatian consumers each month and answers to Q6 (inter alia) were gathered.

When examining the consumer responses to this question, several alternative routines are applicable in obtaining a numerical indicator of inflation expectations. Some of the most influential methods involve the Carlson-Parkin [3] technique, the nonlinear regression method [17] or the Theil [21] and Batchelor [2] approach.

The authors of [19] compare the three methods for 24 individual EU countries, which is, to the best of the authors' knowledge, the most extensive existing study on the subject. Their analysis points to the conclusion that the Batchelor indicator outperforms the other two methods in terms of forecasting accuracy. Therefore, the same method is also applied, postulating that if the best-performing indicator leads to the rejection of the REH, then the two worse indicators would certainly not change the drawn conclusions. Apart from the optimal empirical performance of the Batchelor method, another reason for applying it here is for pure theoretical reasons. Namely, both the Carlson-Parkin and the nonlinear regression methods are seriously criticized for their overrestrictive assumptions (see e.g. [14]).

Without presenting the technical details, the final expression for the Batchelor estimator of inflation expectations is given by equation 1 : 


$$
\pi_{t+12 \mid t}^{e}=\frac{\sum_{t} \pi_{t}}{\sum_{t}\left(U_{t}^{e}-D_{t}^{e}\right)}\left(U_{t}^{e}-D_{t}^{e}\right)
$$

where inflation expectations for 12 months ahead (formed in the period $t$ ) are denoted by $\pi_{t+12 \mid t}^{e}, \pi_{t}$ is the actual inflation rate; while $U_{t}^{e}$ is the fraction of respondents declaring that prices will rise in the following year (answers $a, b$ and $c$ ), and $D_{t}^{e}$ is the share of responses expecting a price decline (answer $e$ ).

The empirical analysis in this paper relies on examining the relationship between actual and expected inflation in Croatia. The period of analysis in this paper is subject to commencing the consumer surveys in Croatia in May 2005. After their commencement, the surveys were carried out on a regular monthly basis, meaning the observed data are collected in monthly intervals. The analyzed period ended in April 2014. In accordance with the standard practice of consumer survey analysis, inflation is expressed in the form of year-on-year rate of HICP price changes.

\section{Methodology}

As can be seen in Table 1, the REH is usually tested empirically by employing standard OLS equations. The OLS framework presumes that the relationship between actual and expected inflation is linear and time-stable. This paper contributes to literature by analyzing potential time variability in the observed relationship utilizing a state space methodology. The remainder of this chapter briefly explains the main differences between linear regression and state space models.

The main assumption in the standard regression analysis is a linear relationship between one dependent variable $y$ and a set of $k$ independent variables. ${ }^{1}$ Deviations from this relationship are modelled as a random process with zero expectation and variance $\sigma_{\varepsilon}{ }^{2}$. The usual way of writing the simple linear regression model is:

$$
y_{t}=\alpha+\beta x_{t}+\varepsilon_{t}, t=1, \ldots, T
$$

where $T$ is the sample size, $\alpha$ and $\beta$ are unknown regression parameters and $\varepsilon_{t}$ are independent and identically distributed random variables (error term), $\varepsilon_{t} \sim \mathrm{N}\left(0, \sigma_{\varepsilon}^{2}\right)$.

As stated in equation (2), regression parameters $\alpha$ and $\beta$ are assumed to be constant. In other words, the assumption is that they do not vary over time,

\footnotetext{
1 For matters of simplicity, the model will be explained for the case of one independent variable in monthly frequencies, but can easily be augmented to a $k$-variable one.
} 
or with changes in the value of some other variable. Macroeconomic analysis rarely anticipates that the parameters will be constant, but this is assumed for reasons of simplicity or a short time span. Various nonlinear methods can be employed to overcome this problem, but various assumptions need to be satisfied, such as the stationarity assumption. This paper utilizes the state space framework since it is one of the most generally accepted econometric models (nesting various other models like VAR and SVAR) and overcomes the non-stationarity problem based on the corresponding model specification.

The general Gaussian state space model is considerably complex, so here a simpler version called the local level model with seasonal ${ }^{2}$ and explanatory variable or the regression model with time-varying $(T V)$ coefficients is described (see [7] for a detailed discussion). The model consists of two main equations: the observation equation and state equation:

$$
\begin{gathered}
y_{t}=z_{t}{ }^{\prime} \mu_{t}+\varepsilon_{t}, \quad \varepsilon_{t} \sim \mathrm{N}\left(0, \sigma_{\varepsilon}{ }^{2}\right) \\
\mu_{t+1}=A \mu_{t}+\eta_{t}, \quad \eta_{t} \sim \mathrm{N}(0, \mathrm{Q}), t=1, \ldots, T
\end{gathered}
$$

where $y_{t}$ is the dependent variable or observation vector, $\mu_{t}^{\prime}=\left(\begin{array}{lllll}\gamma_{1, t} & \gamma_{2, t} & \ldots & \gamma_{11, t} & \alpha_{t} \\ \beta_{t}\end{array}\right)$ is an unobserved $13 \times 1$ vector called the state vector, parameters $\gamma_{1}, \ldots, \gamma_{11}$ describe the seasonal component in time series dynamics, $Q=\operatorname{diag}\left(\sigma_{\omega}{ }^{2}, 0, \ldots, 0, \sigma_{\xi}{ }^{2}, \sigma_{\tau}{ }^{2}\right)$ is a diagonal $13 \times 13$ covariance matrix, vector

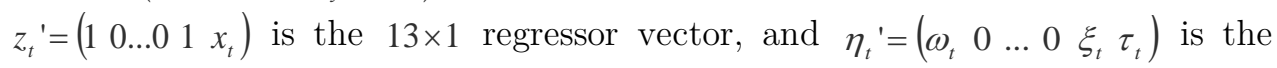
error term. The transition matrix $A$ has a special form where its general term is defined as:

$$
A_{i j}=\left\{\begin{array}{cc}
-1 & i=1, j=1, \ldots, 11 \\
1 & i=2, \ldots, 11, \text { and } j=i+1 \\
1 & i=j=12,13 \\
0 & \text { otherwise }
\end{array}\right.
$$

The expanded equations are:

$$
\begin{gathered}
y_{t}=\gamma_{1, t}+\alpha_{t}+\beta_{t} x_{t}+\varepsilon_{t}, \quad \varepsilon_{t} \sim \mathrm{N}\left(0, \sigma_{\varepsilon}{ }^{2}\right) \\
\alpha_{t+1}=\alpha_{t}+\xi_{t}, \quad \xi_{t} \sim \mathrm{N}\left(0, \sigma_{\xi}{ }^{2}\right) \\
\beta_{t+1}=\beta_{t}+\tau_{t}, \tau_{t} \sim \mathrm{N}\left(0, \sigma_{\tau}{ }^{2}\right) \\
\gamma_{1, t+1}=-\gamma_{1, t}-\gamma_{2, t}-\ldots-\gamma_{11, t}+\omega_{t}, \omega_{t} \sim \mathrm{N}\left(0, \sigma_{\omega}{ }^{2}\right) \\
\gamma_{l, t+1}=\gamma_{l-1, t}, l=2, \ldots, 11
\end{gathered}
$$

\footnotetext{
${ }^{2}$ Recent econometric literature (e.g. [12]) argues that the state space approach to seasonal adjustment outperforms models such as X-11/X-12 ARIMA methods. Therefore, seasonal adjustment is modeled together with other components of a time series.
} 
If the variances in (6-9) are unknown, they can be estimated by maximizing the likelihood function using the optimization procedure based on the quasiNewton scheme BFGS (Broyden-Fletcher-Goldfarb-Shanno algorithm), see [7]. Apart from these variances, the unobserved state values $\gamma_{l(l=1, \ldots, 11), t}, \alpha_{t}$ and $\beta_{t}$ can be estimated using two approaches, depending on whether the first state value is known or unknown. If the first state value is known, the regular Kalman filter can be applied; otherwise, the diffuse Kalman filter is necessary. The latter case applies here, so the diffuse Kalman filter is employed.

In terms of the described state space model, eight $\left(2^{3}\right)$ possible scenarios exist: the seasonal component, the constant term and the slope can be deterministic or stochastic. The seasonal component/constant term/slope is deterministic if the variance $\sigma_{\omega}{ }^{2} / \sigma_{\xi}{ }^{2} / \sigma_{\tau}{ }^{2}$ equals zero (respectively). If all three variances equal zero then the state space model expressed in (6-9) is in fact a classical linear regression model (2) with eleven added seasonal parameters. Therefore, the state space model nests the standard regression model as a special case.

When choosing the optimal state space model, many authors (e.g. [5]) suggest using the Akaike information criterion, defined by:

$$
\text { AIC }=\frac{1}{T}\left[-2 T \log L_{d}+2(q+w)\right]
$$

where $T$ is the number of observations, $\log L_{d}$ is the value of the diffuse $\log$ likelihood function, $q$ is the number of diffuse initial values in the state, and $w$ is the total number of disturbance variances estimated in the analysis.

The usual diagnostic tests should be applied on standardized prediction errors (with state values estimated using Kalman filtering since they are not correlated, [7]): the Jarque-Bera normality test, the Ljung-Box autocorrelation test and the Goldfeld-Quandt test for heteroskedasticity. Apart from the prediction errors $\hat{\varepsilon}_{t}$, the state residuals $\left(\hat{\xi}_{t}, \hat{\tau}_{t}\right.$ or $\left.\hat{\omega}_{t}\right)$ and the observation residuals (estimated using Kalman smoothing, [6]) need to be evaluated. If an absolute value of the standardized observation residual exceeds two, it points to a probable outlier. However if an absolute value of standardized state residual exceeds two, it implies a break in the state dynamics.

\section{Empirical results}

Before empirically testing the validity of the REH, the order of integration is examined for actual and expected inflation. The ADF test was employed and the results are given in Table 2. 


\begin{tabular}{|l|l|l|}
\hline \multicolumn{1}{|c|}{ Variable } & \multicolumn{2}{|c|}{ Deterministic components } \\
\hline & \multicolumn{1}{c|}{ Trend \& intercept } & intercept \\
\hline$\pi_{t}$ & $-2.2372(12)$ & $-1.8490(12)$ \\
\hline$\pi_{t+12 \mid t}^{e}$ & $-4.0470(1)^{*}$ & $-2.3309(1)$ \\
\cline { 2 - 3 } & & \\
\hline
\end{tabular}
chosen using the Akaike information criterion.

Table 2: Unit root test results

Specifically, REH testing on stationary $\pi_{t}$ and $\pi_{t+12 \mid t}^{e}$ implies fitting the following OLS equation:

$$
\pi_{t+12 \mid t}^{e}=\alpha+\beta \pi_{t+12}+\varepsilon_{t+12}
$$

and testing the hypothesis: $H_{0}:(\alpha, \beta)=(0,1)$. For a pair of $I(1)$ variables, the $\mathrm{REH}$ implies the existence of a unique cointegrating vector with equal and opposite coefficients of $\pi_{t+12 \mid t}^{e}$ and $\pi_{t}$. Since the unit root results are rather diverging, the authors have estimated the OLS equation and tested it for (Johansen's) cointegration between the variables. Both approaches resulted in the firm rejection of the REH. ${ }^{3}$ Therefore, the authors considered a state space model defined by equation (13) to examine whether the REH equation can be subject to time-variability of the parameters.

$$
\pi_{t+12 \mid t}^{e}=\gamma_{1, t}+\alpha_{t}+\beta_{t} \pi_{t+12}+\varepsilon_{t+12}
$$

The constant term $\alpha_{t}$ is a measure of consumer bias and represents an exogenous level of inflation as expected by consumers. The slope $\beta_{t}$ is a measure of adjustment between actual and expected inflation. All parameters are allowed to vary over time.

The most important issue in this framework is to test whether consumers are able to predict accurately the actual inflation rate. In other words, testing the unbiasedness of consumer inflation expectations requires testing whether the regression parameters express a statistically significant difference from zero and unity, i.e. $H_{0}:(\alpha, \beta)=(0,1)$.

To acquire a broader picture of the discussed models, all combinations were analyzed with the results given in Table 3 .

${ }^{3}$ The results are omitted due to space limitations, but are available upon request. 


\begin{tabular}{|c|c|c|c|c|c|c|c|c|}
\hline Model & (i) & (ii) & (iii) & (iv) & (v) & (vi) & (vii) & (viii) \\
\hline$\gamma$ & $\mathrm{TV}$ & fixed & $\mathrm{TV}$ & $\mathrm{TV}$ & fixed & fixed & $\mathrm{TV}$ & fixed \\
\hline$\alpha$ & $\mathrm{TV}$ & $\mathrm{TV}$ & fixed & $\mathrm{TV}$ & fixed & $\mathrm{TV}$ & fixed & fixed \\
\hline$\beta$ & $\mathrm{TV}$ & $\mathrm{TV}$ & $\mathrm{TV}$ & fixed & $\mathrm{TV}$ & fixed & fixed & fixed \\
\hline AIC & 0.108 & -0.186 & 0.653 & 0.571 & 0.416 & -0.2 & 1.204 & 1.084 \\
\hline
\end{tabular}

Table 3: Comparison of the analyzed models

The Akaike criteria are the smallest for the second and the sixth model. However, only the sixth model passes all diagnostic testing at the $5 \%$ significance level, as shown in Table 4.

\begin{tabular}{|l|c|c|}
\hline Assumption & \multicolumn{2}{|c|}{ Model } \\
\hline & (ii) & (vi) \\
\hline Normality & 0.03 & 0.07 \\
\hline Autocorrelation (1-12) & 0.27 & 0.34 \\
\hline Heteroskedasticity & 0.41 & 0.49 \\
\hline
\end{tabular}

Note: Table entries represent the obtained p-values

Table 4: Diagnostic tests

According to the results shown in Table 3, the best model is (vi) with a time-varying constant term, fixed slope, and fixed seasonal component. The estimated slope is $\hat{\beta}=-0.0982$, while the estimated value of the constant term varies throughout the analyzed period (as shown in Figure 1).

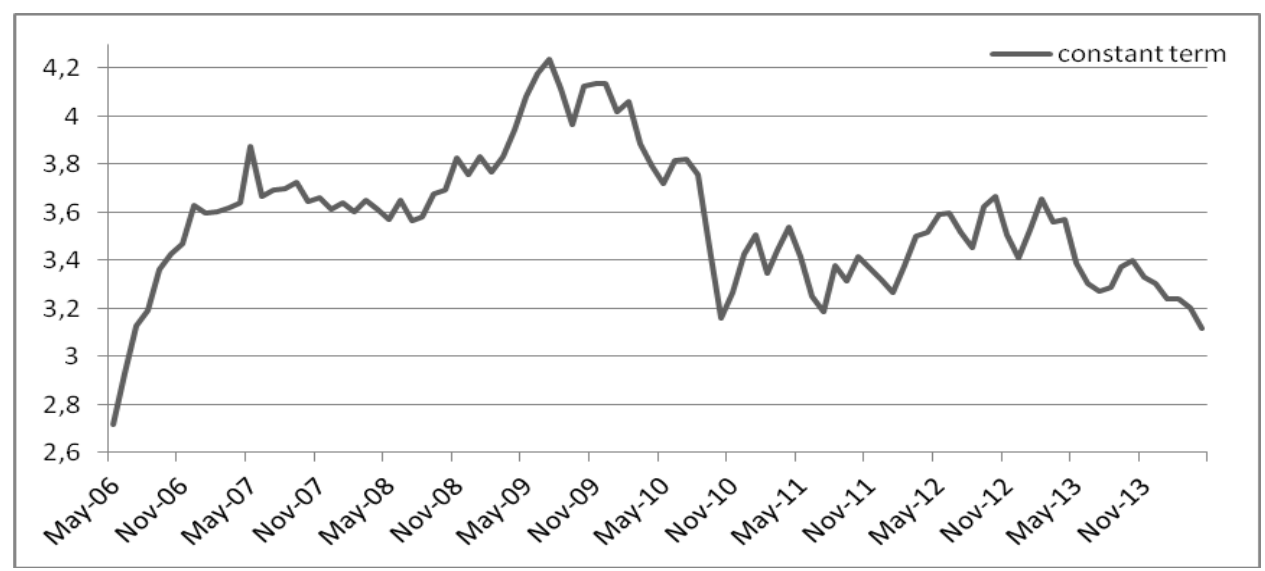

Figure 1: Constant term trend 
Since the constant term is significantly larger than zero throughout the entire period, it implies that Croatian consumers heavily over-estimate actual inflation dynamics. This finding is not at all surprising since most previous findings point to the same conclusion (see $[1,11,13]$ ).

Figure 1 reveals that the necessary condition for consumer expectations to be unbiased $\left(\alpha_{t}=0\right)$ is not met at any time point within the observed period. On the contrary, the estimated constant term (reflecting the expectation bias) varies intensively at around $3 \%$. Its volatility can perhaps be much better explained when observed through the lens of actual inflation dynamics (Figure 2).

The constant term seems to exhibit a kind of lagging behavior with respect to $\pi_{t}$. Specifically, $\alpha_{t}$ was the highest approximately one year after $\pi_{t}$ reached its maximum in July 2008. The consumers obviously react with some delay to changes in their economic environment.

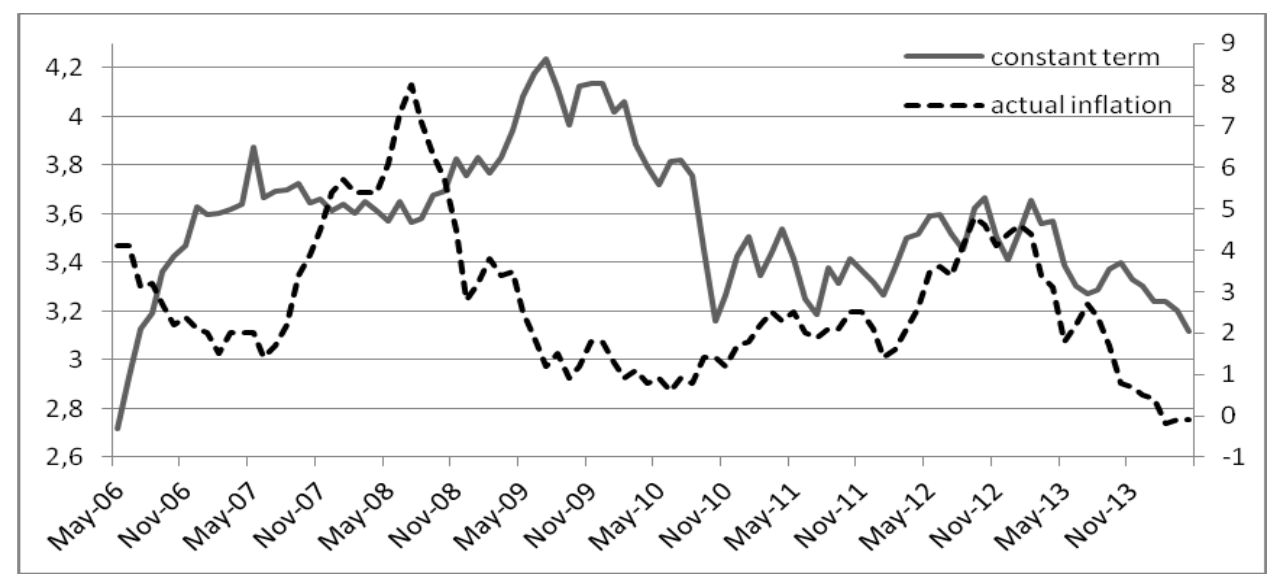

Figure 2: Constant term dynamics with respect to actual inflation movements

The finding that the slope is approximately equal to zero and $\alpha_{t}$ varies around $3 \%$ is attributed to the anchoring heuristic. Specifically, the obtained results reveal that the actual inflation dynamics have hardly any effect on consumer inflation expectations. The consumers produce inflation estimates independently and reappraise them only in case of extreme events. Two such occasions were documented here in the analyzed period.

Firstly, the constant term reached its historical maximum in 2009 due to cost-push factors, i.e. the food and energy price hike on the world markets. Secondly, there is some evidence of growing rationality after the Croatia's EU accession in July 2013. The latter can be attributed to record-low inflation figures after mid-2013. Specifically, it seems that intensified media coverage on 
the issue of falling inflation in the post-accession period has triggered consumers to reappraise their inflation estimates and correct them downwardly.

Figure 3 puts the constant term in relation to the expected inflation.

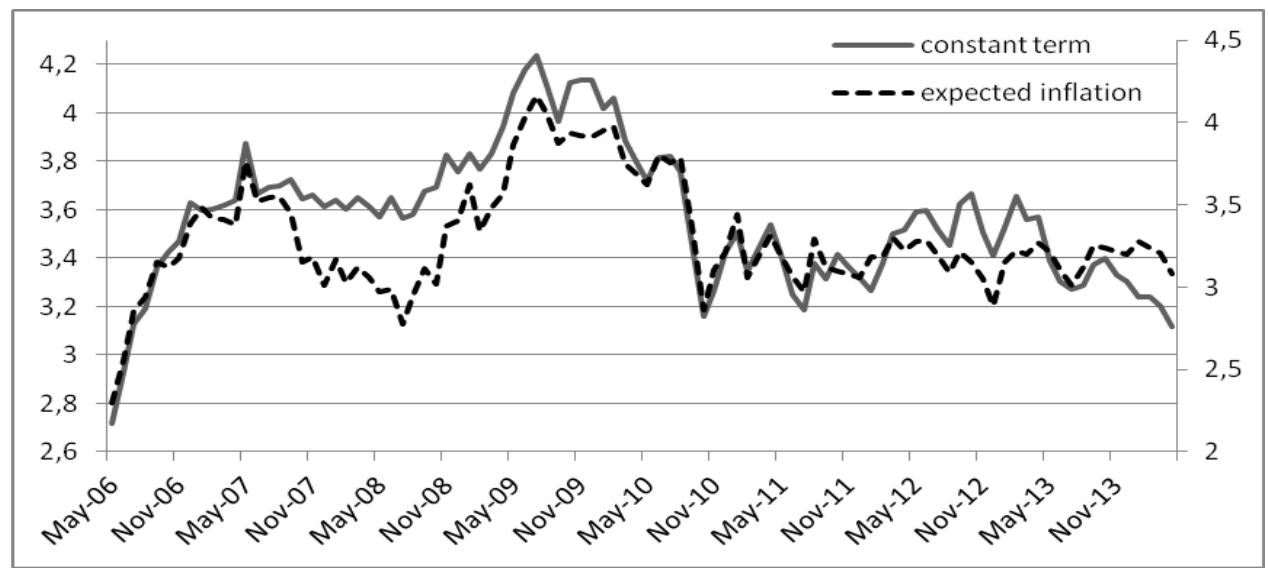

Figure 3: Constant term dynamics with respect to expected inflation movements

It is evident from Figure 3 that expected inflation plays a pivotal role in the REH testing framework. Namely, the constant term is synchronized to a large extent with $\pi_{t+12 \mid t}^{e}$.

The estimated variances are: $\sigma_{\xi}{ }^{2}=0.01678$ (stochastic constant term), $\hat{\sigma}_{\tau}{ }^{2}=0.0 \quad$ (deterministic slope), $\quad \hat{\sigma}_{\omega}{ }^{2}=0.0 \quad$ (deterministic seasonal), and $\hat{\sigma}_{\varepsilon}^{2}=0.0026$.

A further look at the standardized state and observation residuals (Figure 4) reveals no significant outlier or break in constant term dynamics (values that exceed 2 are relatively close to 2 and are not connected to any relevant intervention event).
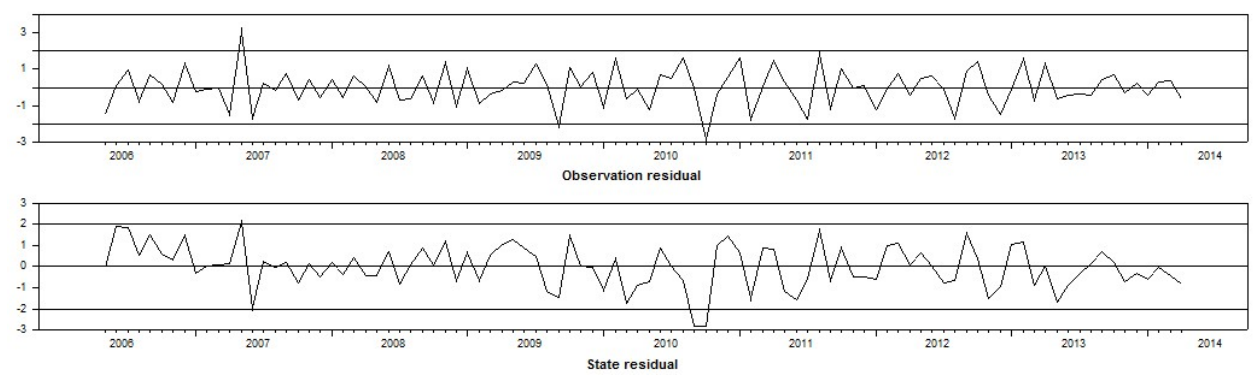

Figure 4: Observation and state residuals for model (vi) 
The rational expectations hypothesis is hence firmly rejected for Croatia, as neither does the constant term equal zero (varies throughout the entire period) nor does the slope equal unity (estimated value is -0.0982).

\section{Conclusion}

This paper examines the relationship between actual inflation and inflation expectations (as measured by consumer surveys) in Croatia. It tests the rational expectations hypothesis in its weaker form, i.e. the unbiasedness of inflation expectations. In order to reveal the time dynamics of the REH relationship, the authors have employed the regression model with time-varying coefficients in a state-space framework. The results reveal that Croatian consumers tend to produce heavily upward-biased inflation estimates, leading to rejection of the REH. The constant term in the REH-testing equation has turned out to be time varying, pointing to the existence of some interesting tendencies. Firstly, the consumer expectation bias is greatest after the 20072008 food and energy price hikes. Contrary to that, is falls to historically low levels after accession to the EU in July 2013, when increased competition caused the consumers to re-evaluate their inflation sentiment.

Since previous inflation studies almost as a rule disprove REH in a strictly linear framework, this study opens up a novel perspective on the issue. Further studies should certainly entail other nonlinear specifications, such as e.g. testing for structural breaks in the the REH equation. Furthermore, the impact of media coverage on price developments (especially after accession to the EU) should be thoroughly examined.

\section{Acknowledgement}

This work has been fully supported by the Croatian Science Foundation under Project no. 3858.

\section{References}

[1] Bakhshi, H. and Yates, A. (1998). Are UK inflation expectations rational? Bank of England Working Paper, No. 81.

[2] Batchelor, R.A. (1986). Quantitative v. qualitative measures of inflation expectations. Oxford Bulletin of Economics and Statistics, 48(2), 99-120. doi:10.1111/j.1468-0084.1986.mp48002001.x.

[3] Carlson, J.A., and Parkin M. (1975). Inflation expectations. Economica, 42, 123138. 
[4] Colander, D., et al. (2008). Beyond DSGE models: Toward an empirically based macroeconomics. American Economic Review, 98(2), 236-240. doi:10.1257/aer.98.2.236.

[5] Commandeur, J. J. F. and Koopman, S. J. (2007). State Space Time Series Analysis. Oxford: Oxford University Press.

[6] Doan, T. A. (2011). State space methods in RATS. Journal of Statistical Software, $41(9)$.

[7] Durbin, J. and Koopman, S. J. (2012). Time Series Analysis by State Space Methods. Oxford: Oxford University Press.

[8] European Commision (2014). Methodological user guide, a user guide to the joint harmonised eu programme of business and consumer surveys. http://ec.europa.eu/economy_finance/db_indicators/surveys/method_guides/in dex_en.htm [Accessed on 16 March 2015].

[9] Forsells, M. and Kenny G. (2004). Survey expectations, rationality and the dynamics of euro area inflation. Journal of Business Cycle Measurement and Analysis, 1, 13-42. doi:10.1787/jbcma-v2004-art3-en.

[10] Galí, J., and Gertler, M. (1999). Inflation dynamics: A structural econometric analysis. Journal of Monetary Economics, 44(2), 195-222. doi:10.1016/s03043932(99)00023-9.

[11] Gramlich, E. M. (1983). Models of inflation expectations formation: a comparison of household and economist forecasts. Journal of Money, Credit and Banking, 15(2), 155-173. doi:10.2307/1992397.

[12] Jain, R. K. (2011). A state space model-based method of seasonal adjustment. Monthly Labor Review, July 2001, 37-45.

[13] Kokoszczyński, R., Łyziak, T. and Stanisławska, E. (2006). Consumer inflation expectations: usefulness of survey-based measures - a cross-country study. Paper presented at the 28th CIRET Conference organized by the Centre for International Research on Economic Tendency Surveys, Rome, Italy, September, 20-23.

[14] Nardo, M. (2003). The quantification of qualitative survey data: A critical assessment. Journal of Economic Surveys, 17(5), 645-668. doi:10.1046/j.14676419.2003.00208.x.

[15] Nestić, D. (2008) Price level convergence and its impact on inflation in Croatia. Economic Review, 59(2), 3-37.

[16] Sabrowski, H. (2008). Inflation expectation formation of German consumers: Rational or adaptive? Working Paper Series in Economics. University of Lüneburg. No.100.

[17] Smith J. and McAleer M. (1995). Alternative procedures for converting qualitative response data to quantitative expectations: An application to Australian manufacturing. Journal of Applied Econometrics, 10(2), 165-185. doi:10.1002/jae.3950100206.

[18] Sorić, P. (2012). Can Croatian consumers predict inflation dynamics?. Economic trends and economic policy, 22(131), 27-57.

[19] Sorić, P., Lolić, I. and Mačkić, M. (2014). An empirical assessment of the expected inflation quantification methods: A pan-European study. Global Review of Business and Economic Research, 9(2), 117-132.

[20] Stock, J. H. (2012). Discussion of "The role of expectations in inflation dynamics". International Journal of Central Banking, 8, Supplement 1, 167-174. 
[21] Theil, H. (1952). On the time shape of economic microvariables and the Munich business test. Review of the International Statistical Institute, 20(2), 105-120. doi:10.2307/1401816. 